\title{
correspondence
}

\section{Genetic engineering guidelines}

SiR, - I was very sorry to read the article by Robert Walgate entitled 'Genetic engineering guidelines: Europe hopeful about collaboration" (1 June, page 331). This referred to a meeting of the ESF's Liaison Committee for Recombinant DNA Research about which no official information has been released to the press nor sought by your journal.

I regret especially the suggestion made in the article that the NIH is misleading the European members of the committee. Our relationships with the NIH and with the Canadian Medical Research Council are, and have always been, extremely frank and open and cooperation between us is excellent. The common spirit which has been created in this committee was in fact particularly in evidence at this meeting.

We have no grounds for believing that the NIH is contemplating only a minor relaxation of their guidelines. On the contrary, we have been in close and continuous contact with them and the preparation of the revisions has involved a series of discussions in which members of the committee have taken part.

I regret that this kind of article can only put at risk the good transatlantic relationships which we have been building up over the last few years. Yours faithfully, F. SCHNEIDER

European Science Foundation, Strasbourg, France

\section{Advantages of nuclear energy}

SIR,-Between one and three people are likely to die per year in Britain in the next few decades as a result of the operations of our civil nuclear power programme. In round figures a coal miner a week dies from an accident, a coal miner a day dies from pneumonoconiosis and several members of the public die every day as a result of breathing the fall-out from the burning of fossil fuels. Even though coal provides more than ten times the proportion of Britain's energy that is provided by nuclear power, the latter clearly has a big advantage.

It is true that far more people are frightened by the smaller but less familiar risks of nuclear power than by the larger but more familiar risks of coal burning. Accordingly, it is natural and indeed perhaps proper for a politician to be more concerned with the risks of nuclear power. Dead people don't have votes.

Frightened people do.

It is however a matter of regret that the chairman of the Conservative

Committee on Energy, Nigel Forman, MP should take so unbalanced a view of the facts (1 June, page 332). Thus he is afraid of the "legitimate doubts" of unspecified dangers from glassified wastes, of which satisfactory blocks in nickel alloy canisters have been made in both Britain and France, and which have been tested in Britain to levels of radiation damage corresponding to a million years of storage. Less than a thousand years of storage would leave them no more active than a good uranium ore, but he cites with approval a Swedish suggestion that unprocessed fuel elements could be stored in copper or ceramic canisters. Probably they could, if put sufficiently far underground. but why should they be safer? After some hundreds of years they really would be worth exhuming by terrorists for the $1 \%$ or so of plutonium contained, which by then would be free enough of gamma-emitters to be processed in an unscreened laboratory without excessive radiation doses to the operators.

Extraction of the remaining traces of plutonium in the glassified blocks is at the practical limits of current technology and to process a hundred tons or so for the plutonium to make a bomb is unlikely ever to be attractive to amateurs. I agree with him that we "are still relatively low on the learning curve about the full potential of a safer, cheaper, alternative energy future". except that I would have said that we don't yet know whether it will ever be possible to make it cheaper or certain that it will ever be safer.

If, hopefully, effective alternatives do appear. they could be used together with nuclear power to conserve irreplaceable oil and coal, not to replace the safer and cleaner nuclear power.

Mr Forman states that a further eighteen months delay could be added without loss to the two years delay already incurred. How can he know this?

Countries such as Japan with no oil and little coal are not going to rest their entire future existence on hopes of alternatives. They must build up a nuclear option capable of supplying their industries in case these hopes are not fulfilled. If THORP as well as the US refused to reprocess, they would have to do it themselves or turn to the USSR. Of course there is a risk-mindeed almost a certainty - of proliferation of nuclear weapons to some extent whatever we do. The necessary data have all been published but I cannot see why the rate of proliferation should be increased if processing is done by large units in a few. countries under close international control rather than separately in a large number of countries which may well refuse any control at all, or do the work in secret, as a result of what they see as a unilateral refusal by the US to implement the positive parts of the non-proliferation treaty.

The real danger before the world seems to me to be the risk that no adequate source of power may be available before the oil gets short. This is indeed the only shadow of rational explanation of the $\$ 200,000$ million being spent annually on armaments. If the alternatives don't work, there could come a time when military control of the Middle East could mean economic control of the world. It may be that even if developed at the maximum possible rate, nuclear power will still not be sufficient in time to avoid disaster. It may be that alternative supplies will already be ample to replace both uranium and coal, in which case two more generations of nuclear power stations will

be enough. But it will be really dangerous not to have the option. Yours faithfully. J. H. FREMLIN

University of Birmingham. UK

\section{Nature's ozone}

SIR,-Working with electrical-discharge devices has made me familiar with the characteristic smell of ozone, which to me has both the "oily" and the "fresh air" qualities often attributed to it. I read about two dozen different science-oriented periodicals per month in the course of my work, but it is only when reading Nature that I detect this same smell. (1 realise that the articles appearing in Nature are

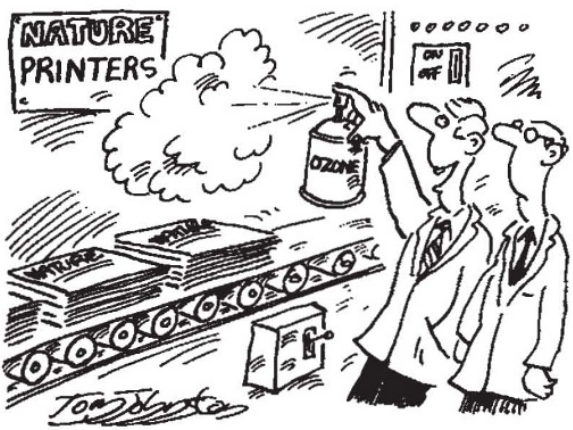

"It's the only air-freshener that doesn't damage the ozone layer"

intended to be stimulating, but hopefully not electrically so.)

I would like to bring to your attention the question of whether ozone indeed is being generated, perhaps by some static phenomenon in the process of turning pages. Or is the smell merely characteristic of the paper or the printer's ink? If the latter case is true, it would be interesting to learn what compound in the periodical mimics the olfactory stimulus of the $\mathrm{O}$, moleculc.

Chicago, Illinois, USA

Yours faithfully.

\section{Anti anti-' $x$ ' antibodies}

SIR,-During the last year, I have noticed that scientists increasingly use the term anti-' $x$ '- antibody both in publishing and lecturing to describe an antibody directed against substance ' $x$ '.

It may be a matter of semantics, but as onc can actually produce antibodies against antibodies (which anti-' $x$ ' already implies), this leads to confusion in nomenclature.

1. as a former scholar of ancicnt Greek. who now works in immunology, would like to suggest that authors and speakers should use the prefix "a n $t i$ ". - against only once when they describe antibodics against substance " $x$ ", such as anti-" $x$ "; anti " $x$ " serum; " $x$ "-antibodies. or antibodies directed against " $x$ ". Yours faithfully, UTt. Grïsthri.-STewart

Darmstadt. West Germany. 